\title{
Research on the Development Path of Guangdong Tourism Economy under the Background of New Maritime Silk Road Construction
}

\author{
Ning Wang \\ Guangdong Mechanical and Electrical Polytechnic, School of Foreign Languages \& International \\ Business, Guangzhou, 510515, China
}

Keywords: New Maritime Silk Road; Guangdong; tourism economy

\begin{abstract}
Since the reform and opening-up, Guangdong's opening-up and tourism economy have developed rapidly. Under the background of the development of the new Maritime Silk Road, Guangdong has become one of the largest tourist distribution centers and tourist destinations in the country, and has become a tourism cooperation on the Maritime Silk Road. The important hub provides a good platform for the construction and development of the new Maritime Silk Road. In recent years, tourism exchange activities between Guangdong Province and the countries along the "Hai Si Line" have become more frequent, tourism economic cooperation has deepened, and new tourism economic growth points have been stimulated, which has brought opportunities for the upgrading and transformation of Guangdong's tourism economy. In this context, by understanding the current situation and problems of Guangdong's tourism economic development under the background of the construction of the new Maritime Silk Road, the countermeasures and suggestions for the development of Guangdong's tourism economy are proposed, and the tourism economic cooperation between Guangdong and the countries along the "Haisi" is promoted. It is of great significance to promote the development of tourism economy.
\end{abstract}

\section{Introduction}

Since the concept of "One Belt, One Road" was put forward in 2013, domestic and foreign countries have paid close attention to the strategic significance and value of the "Belt and Road" and hope to promote the efficient development of the economy. Year 2014. The successful hosting of the "Haibo Fair" in Dongguan, Guangdong Province marks the beginning of a new phase of cooperation between Guangdong and the countries along the Maritime Silk Road ("Haisi" countries). As a sunrise industry related to the development of people's livelihood, tourism has an important value in enhancing the satisfaction of people's material and cultural needs and promoting industrial transformation and consumption upgrading in the context of China's supply-side reform and new normal development. It is of great value to explore the development status and trends of tourism economy and promote the development of innovative tourism, which is the goal of becoming a world tourism power. 


\section{New Maritime Silk Road Construction Background}

Tracing back to history, the route of maritime silk has been around for a long time, and it has been in the Han and Tang Dynasties. As an ancient trade route connecting Asia, Africa and Europe, the Maritime Silk Road has greatly promoted the trade development of neighboring countries and realized the interconnection of national culture and trade. With the continuous evolution and development of history, the strategy of the new Maritime Silk Road is not a continuation of the ancient Silk Road, but a new economic and trade cooperation model that meets the needs of modern economic development. According to the "Vision and Action for Promoting the Construction of the Silk Road Economic Belt and the 21st Century Maritime Silk Road" issued by the Chinese government in March 2015, the scope of the 21st Century Maritime Silk Road was clearly defined, namely Shanghai, Fujian, Guangdong. Hainan and Zhejiang provinces and five provinces. The strategy proposes to actively take advantage of the economic activities of the Bohai Rim, the Pearl River Delta, the Yangtze River Delta and the West Coast of the Straits to accelerate economic and trade cooperation and promote regional economic development.

The construction and development of the new Maritime Silk Road has international and domestic influences. In terms of international influence, multilateral cooperation based on countries along the route has provided new opportunities for the development of economic and trade cooperation between Asia and Europe. Domestically, in the process of deepening reform in China, the construction and development of the new Maritime Silk Road will be an important part of the reform. Through the expansion of cooperation channels, it will provide a good opportunity for domestic technology, talents and capital circulation.

Under the "One Belt, One Road" strategy, Guangdong Province actively carried out relevant tourism cooperation with countries along the Haisi, encouraged the province to promote the development of tourism economy, and attracted foreign tourists. In the past two years, the number of inbound and outbound tourists in Guangdong Province has continuously increased; Under the “One Belt, One Road” strategy, Guangdong Province can rely on the cooperation of cooperative parks to enable more quality tourism enterprises to "go out", continuously strengthen industry and industry exchanges with countries along the route, continuously innovate and optimize industrial structure, and improve the overall layout of the industry.

\section{Current Situation of Tourism Development in Guangdong and Countries along the New Maritime Silk Road Construction}

\subsection{The status quo of Guangdong tourism development}

As the forefront of reform and opening up, the development of tourism economy in Guangdong Province has maintained a steady growth trend. According to the Guangdong Statistical Yearbook 2017, the number of overnight visitors in Guangdong Province in April 2018 was 34.76 million, a year-on-year increase of $11.72 \%$. Tourism revenue in Guangdong Province has increased by as much as seven times. Not only has the income grew steadily, but the number of tourists entering the city and the number of inbound tourists has performed well.

According to the structure of foreign exchange income in Guangdong Province, the current foreign exchange income of Guangdong Province is mainly based on commodity income and labor income, while the latter has an absolute share. Taking 2016 as an example, the province's foreign exchange income totaled 18.57 billion US dollars, of which labor income was 13 billion US dollars. It can be seen that tourism and cross-country tourism between cities in the tourism economy are becoming hot spots. At the same time, the number of five-star hotels in Guangdong Province is currently the highest in the country, and the number of tourist agencies and the number of scenic 
spots are also growing. It is a veritable tourism province in China.

Table 1. Guangdong International Tourism Foreign Exchange Revenue Unit: USD 10,000 (USD 10000)

\begin{tabular}{|c|c|c|c|c|c|c|c|c|}
\hline Indicator & 2000 & 2010 & 2011 & 2012 & 2013 & 2014 & 2015 & 2016 \\
\hline Total province & 411221 & 1243154 & 1390619 & 1562257 & 1627808 & 1707588 & 1788466 & 1857713 \\
\hline Commodity income & 87837 & 300843 & 328186 & 373379 & 418347 & 467879 & 491471 & 553601 \\
\hline Commodity sales revenue & 40834 & 203877 & 230843 & 226527 & 284866 & 326149 & 346426 & 388264 \\
\hline Dietary sales income & 47003 & 96966 & 97343 & 146852 & 133480 & 141730 & 145045 & 165337 \\
\hline Labor income & 323384 & 942311 & 1062433 & 1188877 & 1209461 & 1239709 & 1296996 & 1304112 \\
\hline Scenic tour fee & 14804 & 44754 & 45890 & 62490 & 56973 & 81964 & 54727 & 61305 \\
\hline Accommodation fee & 59216 & 159124 & 175218 & 221840 & 208359 & 225402 & 224810 & 247077 \\
\hline $\begin{array}{l}\text { Long-distance transportation } \\
\text { fee }\end{array}$ & 173535 & 32 & 603529 & 640525 & 579499 & 628392 & 708590 & 626050 \\
\hline Civil aviation & 113086 & 361758 & 492279 & 499922 & 421602 & 461049 & 425834 & 364112 \\
\hline Railway & 43589 & 44754 & 40328 & 59366 & 61857 & 59766 & 55800 & 61305 \\
\hline Ship & 6991 & 45997 & 40328 & 34370 & 35812 & 34152 & 183139 & 144902 \\
\hline Car & 9869 & 41024 & 30594 & 46868 & 60229 & 73426 & 43817 & 55732 \\
\hline City transportation fee & 7813 & 26106 & 26422 & 28121 & 35812 & 30737 & 36306 & 40870 \\
\hline $\begin{array}{l}\text { Postal telecommunications } \\
\text { fee }\end{array}$ & 9458 & 19890 & 20859 & 21872 & 161153 & 22199 & 27006 & 37154 \\
\hline Cultural entertainment fee & 37010 & 94480 & 87609 & 112482 & 29301 & 136607 & 85131 & 102732 \\
\hline Other & 21548 & 104425 & 102906 & 101547 & 138364 & 114408 & 160425 & 188923 \\
\hline
\end{tabular}

With the geographical advantage of facing the sea, Guangdong Province has the longest coastline in the country. It is a Southeast Asian country across the sea. It can directly reach the Middle East, Central Asia and Africa and other countries and regions across the South China Sea. It is the new Maritime Silk Road. Important port. According to the data, the development of Guangdong Province has been good in recent years, and it has already carried out the "application for heritage" of culture and tourism, and has carried out heritage protection work in several cities. Many tourism resources have been included in the core project of tourism economic development in Guangdong Province. For example, Huangpu Ancient Port, 13th ruins, Xuwen Dahan Sandun Site and Guangzhou Nanhai Temple. At the same time, Guangdong Province is actively constructing tourism routes with the theme of the new Maritime Silk Road to develop integrated and personalized tourism projects. Guangdong is actively cooperating with countries along the Haisi to jointly carry out tourism and cultural activities and has accumulated a large number of international tourism exchange experiences. A number of documentary films on the theme of Haisi tourism filmed in Guangdong Province have also brought a high degree of influence to the development of tourism economy.

\subsection{Status quo of tourism cooperation between Guangdong and Haisi countries and regions}

\subsubsection{Tourism cooperation between Guangdong Province and Singapore}

As a tourism-oriented country, Singapore's tourism economy is developing rapidly, and China has always been one of Singapore's main source of tourists. Under the pillar industry status of the tourism industry, Singapore's tourism industry is very mature, not only has good traffic conditions, 
but also has a complete tourism supporting service and tourism marketing strategy in infrastructure construction. It can be said that in terms of economic development after tourism, Singapore has rich experience and has been constantly innovating. It is one of the "top ten travel countries in the world". Since 2014, Guangdong Province has reached a tourism cooperation and exchange relationship with Singapore, which has promoted the growth of tourism consumption between the two sides. According to statistics, in recent years, Singapore is one of the important source markets for Guangdong. The number of visitors to Singapore in Singapore has increased six-fold in the past decade, which has brought good opportunities for tourism economic cooperation and cooperation.

\subsubsection{Tourism cooperation between Guangdong Province and Malaysia}

Also as a tourist economy country, Malaysia's tourism foreign exchange income is very high. Whether in terms of popularity, geography or culture, Guangdong Province and Malaysia have a wide exchange. Therefore, in the development of regional tourism economy, it has strong complementarity and deep cooperation advantages. Statistics show that the number of tourists from Malaysia to Guangdong has risen sharply in the past decade, laying a solid foundation for tourism economic cooperation between the two sides.

\subsubsection{Tourism cooperation between Guangdong Province and Indonesia}

As a maritime neighbor, China began a comprehensive strategic cooperation relationship with Indonesia from the beginning of Zheng He's voyages to the West. At the same time, as a core country of ASEAN, Indonesia has had in-depth economic and trade cooperation with Guangdong Province since ancient times and is an important re-export base for Guangdong's export trade. According to some survey reports, Indonesia has a large number of foreign tourists, most of them Chinese tourists, even in the context of the global economic downturn in 2012-2013. From 1998 to 2018, the number of visitors from Indonesia to Guangdong Province increased by $470 \%$, indicating that the attractiveness of Guangdong Province to Indonesian tourists is also increasing.

\subsubsection{Tourism cooperation between Guangdong Province and Thailand}

For many years, Thailand has not only been a leader in tourism in Southeast Asia, but also the preferred country for outbound tourists in Guangdong Province. At the same time, Guangdong Province has also received a large number of tourists from Thailand in recent years. According to information released by the National Tourism Administration of Thailand, in the tourist market of Thailand's tourism industry, China, especially in Guangdong, has a very high customer market and a more mature development. Therefore, Thailand attaches great importance to the tourism market in Guangdong.

\subsubsection{Tourism cooperation between Guangdong Province and South Korea}

In recent years, the scale of bilateral tourism economic trade between China and South Korea has continued to expand. After the official signing of the China-South Korea FTA in 2015, it has brought new growth points for the development of the tourism economy. Objectively speaking, the cultural inclusiveness of China and South Korea is relatively high, which has brought great opportunities for the deep cooperation between the two sides in the tourism economy. The data shows that the number of Chinese tourists visiting Korea has been rising in recent years, and it is mainly based on shopping. Food, cosmetics and clothing are the main shopping targets. The number of visitors to South Korea to visit Guangdong Province has also increased significantly, with a growth rate of $2000 \%$ in 20 years. 


\section{Performance of Tourism Cooperation between Guangdong and Haisi Countries and Regions}

\subsection{Lack of cooperation systemic}

At present, the development of tourism cooperation between Guangdong, Hong Kong and Macao is relatively stable. However, in terms of tourism cooperation with countries along the Haisi, due to the interests of many parties, many interest disputes have arisen, resulting in inability to deepen cooperation. With the increasing influence of the "One Belt, One Road" strategy, the tourism projects developed by many parties are too inefficient, and there are blind problems. Each country has its own policies and does not take into account the principle of systematic cooperation, which leads to the development of tourism economic cooperation. With many different situations and problems, up to now, Guangdong Province has not yet established a sound external cooperation mechanism, and has not established a systematic and scientific cooperation system with the countries along the line in the tourism economy.

\subsection{Tourism industry elements encounter bottlenecks}

From the traditional six elements of the tourism economy: "eat, live, travel, travel, purchase, entertainment", to the new six elements of the National Tourism Administration Director Li Jinzao, "business, education, learning, leisure, love, and oddity", currently Guangdong In terms of transformation and upgrading, innovation and development, the province's tourism economic development still lacks motivation and has not improved its core competitiveness. Under the construction of emerging tourism products such as novel tourism, research tourism and health tourism, there is a lack of projects with connotation and quality assurance. Although the Guangdong Tourism Development Plan outlines a number of key development contents and strategies, in the actual implementation process, the upgrading and transformation of the tourism economy in Guangdong Province still faces problems such as slow development.

\subsection{Tourism development model}

At present, the development of tourism economy in Guangdong Province, under the background of the construction of the new Maritime Silk Road, its tourism development model mainly faces the following four major problems: First, the resource quality is low, mainly based on the resources of middle and low-end tourism projects, lacking internationally renowned brands. Class resources. In short, although Guangdong Province has four famous mountains of Luofu, Danxia, Xiqiao and Dinghu, and has many national forest parks and nature reserves, there are no world natural and cultural heritages like Zhangjiajie and Huangshan. In terms of the popularity and cultural connotation of tourism resources, it still needs to be improved. Secondly, the direction of regional development is not clear, and there is a lack of correct and profound awareness of the development of tourism resources market. This has led to the unclear positioning of many tourism projects and even "constructive destruction". "There are problems that damage the good image of regional tourism. The third is the lack of characteristics in the planning and construction of scenic spots. The similarities between creativity and projects are conspicuous, leading to the problem of waste of resources and repetitive construction. Even the construction of many theme resorts exists. The topic is too consistent; the fourth is the construction of tourist attractions in the tourist area needs to be strengthened, lack of innovative projects, lack of personalized tourism regional theme construction, and no in-depth analysis of the development trend of tourism economy, does not cater to the ever-changing tourist tourism needs, The attraction of its scenic spots continues to decline. 


\subsection{Tourism marketing efforts and strategic issues}

At this stage, in the context of the construction and development of the new Maritime Silk Road, Guangdong Province should pay special attention to the "travel deficit" problem. In the case of an increasing number of outbound tourists and no increase in the number of inbound tourists, official marketing efforts and Strategic issues. According to survey data, the current stay time of inbound tourists in Shanghai is 4-5 days, the stay time of inbound tourists in Beijing is about one week, and the inbound tourists stay in Guangzhou City of Guangdong Province is only 2-4 days. In this context, Guangdong Province needs to re-examine the current tourism marketing situation, to classify different market segments for different transit groups, and to develop targeted and attractive products to attract tourists and retain tourists.

5. The Development Path of Guangdong tourism Economy under the Background of the Construction of the new Maritime Silk Road

\subsection{Deepen the deep cooperation and industrial investment between tourism enterprises}

In the context of the construction of the new Maritime Silk Road, Guangdong Province should continuously deepen its tourism economic cooperation with countries along the route, strengthen industrial investment, expand business contacts from a horizontal perspective, learn from each other and improve management and service levels, and promote cooperation among various travel agencies. Develop and promote regional tourism projects, accelerate the business relationship between the scenic areas, and strengthen the integration of tourism resources. From the vertical perspective, countries and enterprises along the line should strengthen cooperation, encourage tourism enterprises in Guangdong Province to cooperate with enterprises in the countries along the route, adopt cooperation agreements, shareholdings, etc., establish strategic alliances for tourism supply chains, build network-type consortiums, and improve supply chains. The interest coordination mechanism promotes the benign cooperation and sustainable development among tourism enterprises. With the characteristics of abundant resources, it is recommended that Guangdong Province actively promote the investment cooperation of the tourism industry in accordance with the principles of rational allocation, joint development and resource integration, optimize the conditions for attracting investment, encourage enterprises to go out, and welcome the cooperation in the development of Guangdong by means of acquisition and equity participation. The tourism attractions project in the province will create a modern investment and financing platform for the tourism economy.

\subsection{Optimize tourism industry elements and construct a joint development model}

At this stage, the types of tourism resources in Guangdong Province mainly include two aspects: on the one hand, diversified tourist landscapes, such as characteristic coastlines, leisure and holiday centers, high-end golf courses, scenic spots and historic sites, "Maba People” site in Qujiang County, and Guangdong Province. The four famous mountains, six national historical and cultural cities and the "folk culture village" man-made landscape, the natural scenery of the Qixingyan in the Zhaoqing Festival; on the other hand, the Lingnan garden culture landscape of the religious culture and history and culture, and the cultural landscape of Guangdong. Along with the continuous improvement of tourism consumption level, in the face of the growth of inbound tourists, while developing tourism products, Guangdong Province still needs to consider the issue of maintaining ecological balance and moderate capacity to avoid ecological imbalances. 


\subsection{Explore marketing promotion models and build innovative institutional mechanisms}

In terms of marketing promotion, it is first recommended to adopt a joint promotion approach, with the attraction of the Pearl River Delta tourism circle, expand the scope of influence, and build a good ecological model for joint marketing promotion. Secondly, we must adopt internal and external joint propaganda and marketing methods, expand tourism promotion channels in China, integrate market resources abroad, actively promote tourism enterprises, carry out the strategic layout of "going out", seek more cooperation, and improve the details of tourism theme activities. Learn from the tourism development experiences of countries along the route and carry out more tourism culture and exchange activities.

\section{Summary}

It is suggested that Guangdong Province should take the innovation of institutional mechanism as the foundation, construct an innovative tourism economic system and mechanism, draw on the mature tourism economic development model, and combine its own actual conditions to carry out systematic upgrading of the industry, including tourism elements, entry and exit management and Project development and other aspects.

\section{Acknowledgement}

Research Platform and Scientific Research Project of Guangdong Provincial Education Department (2017GWTSCX009), Research Project of National Science and Technology Thought Library of Guangzhou City in 2018 (2018SX009), Humanities and Social Science Research Project of Guangdong Electromechanical Vocational and Technical College (YJZD-2018-02).

\section{References}

[1] Zhang Ying, Wu Xinlei.Research on Supply Side Reform and Grey Prediction of Tourism Industry in Guangdong[J].Journal of Jiaying University,2016,34(11):73-78.

[2] Song Shimeng, Jiang Shengyi. Research on Tourism Development Level of Cities in Guangdong Province-Based on Principal Component Analysis and Cluster Analysis Method[J].Journal of Finance and Economics Research,2017(01):40-49.

[3] Fan Xingang. Research on the Comprehensive Development and Marketing Strategy of Guangdong Sports Tourism Resources in the Period of Social Economy Transformation[J].Journal of Heze University, 2017,39(02):95-99.

[4] Feng Xuegang, Tang Rui. Research on the Efficiency of Inbound Tourism Markets in Provinces and Cities along the 21st Century Maritime Silk Road[J].Journal of Nanjing Audit University, 2017, 14(04): 1-11.

[5] Li Hongjie, Lin Xinwei, Lin Zaiming. Experiences of the construction of the 21st Century Maritime Silk Road in relevant provinces and cities and its reference to Fujian [J]. Fujian Forum (Humanities and Social Sciences Edition), 2016 (04): 160-166.

[6] Tang Rui. The Impact of Tourism Enterprises on the Efficiency of Inbound Tourism Market—An Empirical Study Based on Five Provinces and Cities in the 21st Century Maritime Silk Road[J].Journal of Jinan University(Philosophy and Social Sciences),2018,40(03 ):123-132 